University of Nebraska - Lincoln

DigitalCommons@University of Nebraska - Lincoln

USDA National Wildlife Research Center - Staff Publications
U.S. Department of Agriculture: Animal and Plant Health Inspection Service

2007

\title{
Temperature Effects on Soil Dielectric Properties Measured at 50 $\mathrm{MHz}$
}

Mark S. Seyfried

University of California - Santa Barbara, mseyfrie@nwrc.ars.usda.gov

Laura E. Grant

University of California - Santa Barbara

Follow this and additional works at: https://digitalcommons.unl.edu/icwdm_usdanwrc

Part of the Environmental Sciences Commons

Seyfried, Mark S. and Grant, Laura E., "Temperature Effects on Soil Dielectric Properties Measured at 50 MHz" (2007). USDA National Wildlife Research Center - Staff Publications. 1065.

https://digitalcommons.unl.edu/icwdm_usdanwrc/1065

This Article is brought to you for free and open access by the U.S. Department of Agriculture: Animal and Plant Health Inspection Service at DigitalCommons@University of Nebraska - Lincoln. It has been accepted for inclusion in USDA National Wildlife Research Center - Staff Publications by an authorized administrator of DigitalCommons@University of Nebraska - Lincoln. 


\title{
Temperature Effects on Soil Dielectric Properties Measured at $50 \mathrm{MHz}$
}

\author{
Mark S. Seyfried* and Laura E. Grant
}

\begin{abstract}
In recent years a number of soil water monitoring instruments have been developed and made commercially available. These instruments generally respond to the complex soil dielectric permittivity and operate at frequencies between 10 and $150 \mathrm{MHz}$. Although there is some evidence that these instruments are sensitive to temperature change in certain soils, little empirical data exists describing the degree of this sensitivity. We quantified temperature effects on both the real and imaginary components of the complex permittivity for 19 soils collected around the United States using the Hydra Probe soil water sensor, which operates at $50 \mathrm{MHz}$. We found that the real component response ranged from positive to negative such that the effect of a $40^{\circ} \mathrm{C}$ temperature change resulted in a maximum apparent water content change of $\pm 0.028 \mathrm{~m}^{3} \mathrm{~m}^{-3}$ among soils. The effect of temperature on the imaginary component was as much as six times greater than on the real component, changing about $2 \%$ ${ }^{\circ} \mathrm{C}^{-1}$, which is similar to that observed for electrical conductivity. The high imaginary component sensitivity to temperature is probably responsible for the high temperature sensitivity noted for commercial soil water sensors because they generally respond to a composite of both components. In addition, there was a strong linear correlation $\left(R^{2}=0.81\right)$ between the effect of temperature on the calculated soil water content and the magnitude of the imaginary component. While this relationship suggests the possibility of calculating temperature effects on Hydra Probe-calculated soil water content in the field, it applies only to saturated soil conditions at present.
\end{abstract}

ABBREVIATIONS: TDR, time domain reflectometry.

Coil water content $\left(\theta, \mathrm{m}^{3} \mathrm{~m}^{-3}\right)$ is a basic hydrologic param$\checkmark$ eter that affects groundwater recharge, surface water flow, transpiration, and carbon fixation. Electronic monitoring of $\theta$ facilitates the study of those processes by providing detailed temporal data. Most instruments currently in use measure soil dielectric permittivity, directly or indirectly, and then calculate $\theta$ with an equation relating permittivity to $\theta$ (e.g., Topp et al., 1980). Unfortunately, the relationship between permittivity and $\theta$ is not unique but is affected by the measurement frequency, soil properties (e.g., electrical conductivity, clay mineralogy, clay content), and temperature (Or and Wraith, 1999; Jones and Friedman, 2000; Friedman and Robinson, 2002). We focus on temperature because, although temperature effects on time domain reflectometry (TDR) have received some attention (e.g., Persson and Berndtsson, 1998; Or and Wraith, 1999; Evett et

M.S. Seyfried, USDA-ARS-NWRC, 800 Park Blvd., Boise, ID 93712; L.E. Grant, 3310 Bren School of Environmental Science and Management, Univ. of California, Santa Barbara, CA 93106-5131. Mention of manufactures is for the convenience of the reader only and implies no endorsement on the part of the authors or the USDA. Received 30 Dec. 2006. *Corresponding author (mseyfrie@nwrc.ars.usda.gov).

Vadose Zone J. 6:759-765

doi:10.2136/vzj2006.0188

(C) Soil Science Society of America

677 S. Segoe Rd. Madison, WI 53711 USA.

All rights reserved. No part of this periodical may be reproduced or transmitted in any form or by any means, electronic or mechanical, including photocopying, recording, or any information storage and retrieval system, without permission in writing from the publisher. al., 2005; Logsdon, 2005b), temperature effects on other commercial instruments are relatively unknown even though these instruments are widely used and evidence suggests that they may experience dramatic temperature effects (Baumhardt et al., 2000; Seyfried and Murdock, 2001; Blonquist et al., 2005).

Issues related to the use of soil dielectric properties to determine $\theta$ result, at least in part, from to the fact that permittivity $\left(\varepsilon^{*}\right)$ is a complex number. Thus,

$\varepsilon_{\mathrm{r}}^{*}=\varepsilon_{\mathrm{r}}^{\prime}-j \varepsilon_{\mathrm{r}}^{\prime \prime}$

where

$\varepsilon_{\mathrm{r}}^{*}=\varepsilon^{*} / \varepsilon_{0}$

and $\varepsilon_{\mathrm{r}}^{*}$ is the relative complex permittivity, $\varepsilon_{\mathrm{r}}^{\prime}$ is the real component of $\varepsilon_{\mathrm{r}}^{*}, \varepsilon_{\mathrm{r}}^{\prime \prime}$ is the imaginary component of $\varepsilon_{\mathrm{r}}^{*}, \varepsilon_{0}$ is the free space permittivity $\left(8.854 \times 10^{-12} \mathrm{~F} \mathrm{~m}^{-1}\right)$, and $j=\sqrt{ }-1$. The real component is related to the amount of energy stored in a material as molecules shift alignment in an alternating electric field, and the imaginary component, sometimes called the loss factor, is related to the energy lost in that applied field. The imaginary component is the result of two processes, electrical conduction and molecular relaxation (Topp et al., 2000; Robinson et al., 2003). These are related to $\varepsilon_{\mathrm{r}}^{\prime \prime}$ as follows:

$\varepsilon_{\mathrm{r}}^{\prime \prime}=\varepsilon_{\mathrm{r}, \mathrm{mr}}^{\prime \prime}+\left(\sigma / 2 \pi f \varepsilon_{0}\right)$ 
where $\varepsilon^{\prime \prime}{ }_{\text {r,mr }}$ is the relative permittivity due to molecular relaxation, $\sigma$ is the low frequency (dc) electrical conductivity, and $f$ is the measurement frequency. Soil water instruments make use of the strong correlation between $\varepsilon_{\mathrm{r}}^{\prime}$ and $\theta$ observed in soils. In nondispersive, nonlossy soils, where $\varepsilon_{\mathrm{r}}^{\prime}>>\varepsilon_{\mathrm{r}}^{\prime \prime}$, the $\varepsilon_{\mathrm{r}}^{\prime}(\theta)$ relationship is robust and temperature effects can be estimated with reasonable accuracy for both TDR (Pepin et al., 1995) and other commercial instruments (Seyfried and Murdock, 2001, 2004), assuming that soil water has the known dielectric properties of pure water. Complications arise as $\varepsilon_{\mathrm{r}}^{\prime \prime}$ increases.

High $\varepsilon_{r}^{\prime \prime}$ values affect $\theta$ estimation in two ways. First, while $\theta$ calculations are based on the $\varepsilon_{\mathrm{r}}^{\prime}(\theta)$ relationship, most instruments respond to both $\varepsilon_{\mathrm{r}}^{\prime}$ and $\varepsilon_{\mathrm{r}}^{\prime \prime}$. For example, the apparent permittivity $\left(\varepsilon_{\mathrm{a}}\right)$ is generally used to calculate $\theta$ from TDR data. It is determined for a sinusoidal plane wave propagating along a transmission line (assumed analogous to TDR signal propagation) and is related to both $\varepsilon_{\mathrm{r}}^{\prime}$ and $\varepsilon_{\mathrm{r}}^{\prime \prime}$ as follows:

$\varepsilon_{\mathrm{a}}=\varepsilon_{\mathrm{r}}^{\prime} / 2\left\{1+\left[1+\left(\varepsilon_{\mathrm{r}}^{\prime \prime} / \varepsilon_{\mathrm{r}}^{\prime}\right)^{2}\right]^{0.5}\right\}$

Clearly, high values of $\varepsilon_{\mathrm{r}}^{\prime \prime}$ elevate $\varepsilon_{\mathrm{a}}$ and confound $\theta$ estimation. With other instruments the relationship may be different, but the problem remains that both components affect the measured variable. The second way is the less widely recognized but well documented dispersion of $\varepsilon_{r}^{\prime}$. That is, soil $\varepsilon_{r}^{\prime}$ itself may be elevated above that expected, assuming that soils have the same dielectric properties as independent mixtures of soil particles and free water (Campbell, 1990; Saarenketo, 1998; Robinson et al., 2005; Chen and Or, 2006). Chen and Or (2006) have shown that these effects may be attributed to interfacial polarization (or the Maxwell-Wagner effect).

The issue of high $\varepsilon_{r}^{\prime \prime}$ is especially important when working with the commercial (non-TDR) soil water sensors mentioned above because $\varepsilon_{\mathrm{r}}^{\prime \prime}$ is strongly dependent on the measurement frequency (see Eq. [3]). It turns out that $\varepsilon_{\mathrm{r}}^{\prime \prime}$ tends to decline, in some soils dramatically, as $f$ increases from the $\mathrm{KHz}$ to the $\mathrm{MHz}$ region (Saarenketo, 1998; Robinson et al., 2005; Chen and Or, 2006). Because the commercial instruments generally operate at relatively low frequencies $(10-150 \mathrm{MHz})$, the $\varepsilon_{\mathrm{r}}^{\prime \prime}$ term will tend to be greater for those instruments than for TDR, which operates at frequencies between 600 and $1000 \mathrm{MHz}$ (Robinson et al., 2005).

The effects of temperature on $\theta$ estimation are strongly related to $\varepsilon_{\mathrm{r}}^{\prime \prime}$. Both $\varepsilon^{\prime \prime}{ }_{\mathrm{r}, \mathrm{mr}}$ and $\sigma$ are temperature dependent. The effect of increasing temperature on $\varepsilon^{\prime \prime}{ }_{\mathrm{r}, \mathrm{mr}}$ is to shift the $\varepsilon_{\mathrm{r}}^{\prime \prime}(f)$ relationship (which is declining under the conditions of interest) to the right, resulting in elevated $\varepsilon_{r}^{\prime \prime}$ (Tinga, 1992). The effect of temperature on $\sigma$ is well established and results in an increase with temperature of about $2 \%{ }^{\circ} \mathrm{C}^{-1}$ (Or and Wraith, 1999). Thus, both processes cause an increase in $\varepsilon_{\mathrm{r}}^{\prime \prime}$ with temperature, which will tend to result in an apparent increase in $\theta$. This trend is opposed to that predicted from the dielectric properties of pure water (Weast, 1986).

Although a general understanding of these issues has emerged in recent years, few experimental data have documented the sensitivity of $\varepsilon_{\mathrm{r}}^{\prime}$ or $\varepsilon_{\mathrm{r}}^{\prime \prime}$ to soil type or to temperature change. Similarly, few data have described the linkage of $\varepsilon_{r}^{\prime}$ and $\varepsilon_{\mathrm{r}}^{\prime \prime}$, particularly with respect to temperature effects. The direct effect of these processes on $\theta$ estimation, as well as the potential for improved measurement accuracy, has led others to recommend that greater attention be devoted to the separation of $\varepsilon_{r}^{\prime}$ and $\varepsilon_{\mathrm{r}}^{\prime \prime}$ in future research (Blonquist et al., 2005; Robinson et al., 2003). Consistent with that recommendation, we previously described how the $\varepsilon_{\mathrm{r}}^{\prime}(\theta)$ relationship for different soils is affected by $\varepsilon_{\mathrm{r}}^{\prime \prime}$ (Seyfried et al., 2005). In this paper we extend that analysis to consider temperature effects. The objectives of this work are (i) to quantify the effect of temperature on $\varepsilon_{r}^{\prime}$ and $\varepsilon_{r}^{\prime \prime}$ for a wide variety of soils and (ii) to examine the relationship between $\varepsilon_{\mathrm{r}}^{\prime}(\mathrm{T})$ and $\varepsilon_{\mathrm{r}}^{\prime \prime}$ to evaluate the potential for predicting temperature effects from $\varepsilon_{r}^{\prime \prime}$ information. Our data were collected only at $50 \mathrm{MHz}$, using Hydra Probe soil water sensor (Stevens Water Monitoring Systems, Portland, OR), and therefore have direct implications for commercial instruments that operate near that frequency. The results should also provide useful insights into the dielectric properties of soils in general.

\section{Materials and Methods}

\section{Hydra Probe Description}

The design and measurement approaches behind the Hydra Probe soil water sensor used in our analysis are based on the work of Campbell $(1988,1990)$ and described in greater detail in Seyfried et al. (2005). When a voltage is applied to a coaxial probe, the reflected signal is related to the probe impedance $\left(Z_{\mathrm{p}}\right)$ such that

$\frac{Z_{\mathrm{p}}}{Z_{\mathrm{c}}}=\frac{1+\Gamma}{1-\Gamma}$

where $Z_{\mathrm{c}}$ is the characteristic impedance of the coaxial cable (determined independently) and $\Gamma$ is the complex ratio of the reflected voltage to the incident voltage. Under these conditions, the probe impedance is determined by the electrical properties of the probe itself $\left(Z_{0}\right)$ and the $\varepsilon_{\mathrm{r}}^{*}$ of the media in the sensing volume (e.g., soil). These are related by

$Z_{\mathrm{p}}=\frac{Z_{0}}{\sqrt{\varepsilon^{*}}} \cot \operatorname{anh} \frac{\omega L \sqrt{\varepsilon^{*}}}{c} j$

where $L$ is the electric length of the probe and $c$ is the speed of light (Campbell, 1990). By inverting Eq. [6], $\varepsilon_{\mathrm{r}}^{*}$ (and therefore $\varepsilon_{\mathrm{r}}^{\prime}$ and $\left.\varepsilon_{\mathrm{r}}^{\prime \prime}\right)$ can be solved for given the measured reflected voltages (Campbell, 1990). Note that the value of $\varepsilon_{\mathrm{r}}^{\prime \prime}$ obtained in this way does not distinguish between $\varepsilon^{\prime \prime}{ }_{\mathrm{r}, \mathrm{mr}}$ and $\sigma$.

The Hydra Probe consists of a 4-cm diameter cylindrical head that has four $0.3-\mathrm{cm}$ diameter tines that protrude 5.8 $\mathrm{cm}$. These are arranged such that a centrally located tine is surrounded by the other three tines in an equilateral triangle with 2.2-cm sides. A $50-\mathrm{MHz}$ signal is generated in the head and transmitted via planar waveguides to the tines, which constitute a coaxial transmission line. In addition, the Hydra Probe has a thermistor embedded in the sensor head to measure temperature. The raw signal output is four analog dc voltages that are transmitted to a data logger (or other voltage measuring device). Manufacturer-supplied software uses the first three voltages to calculate $\varepsilon_{\mathrm{r}}^{\prime}$ and $\varepsilon_{\mathrm{r}}^{\prime \prime}$ (using Eq. [6]) and the fourth to calculate temperature. 


\section{Experimental Procedures}

The soil temperature data were collected in conjunction with a previously published study of soil water calibration (Seyfried et al., 2005). The soils used were selected to represent a wide range of textures and mineralogy and have been described in Seyfried et al. (2005). A table summarizing the soil properties is included here (Table 1).

The temperature sensitivity of each soil was determined at two different water contents: oven-dry and effective saturation. Triplicate samples of oven-dry soil were packed uniformly into plexiglas Tempe cells as described by Seyfried et al. (2005).

The surface was covered with parafilm to prevent evaporation, and the sensor was placed vertically (tines inserted downward from the top) into the cell. The three replicates were run simultaneously. All data were collected and stored on a data logger. In addition, a fourth "dummy" cell also packed with ovendry soil and instrumented with a thermistor, was prepared.

The four cells were then placed in a controlled-temperature incubator. Temperature was varied from 45 to $5^{\circ} \mathrm{C}$ in $10^{\circ} \mathrm{C}$ increments. Thermal equilibrium was assumed when the air temperature in the chamber and the dummy cell temperature were within $0.5^{\circ} \mathrm{C}$. Each soil-temperature combination was measured a minimum of 20 times. Following the oven-dry readings, distilled, deionized water was added slowly from below until glistening at the surface indicated effective soil saturation. Temperature sensitivity data were then collected in the same manner as for the oven-dry soil with the dummy cell saturated. Water content at effective saturation was determined gravimetrically.

In addition, we were concerned that there may be some instrument response to temperature independent of soil conditions, for example, due to the electronic components of the instruments. To evaluate the instrument response we placed the same Hydra Probe sensors in the incubation chamber suspended in air and applied temperatures ranging from $45^{\circ} \mathrm{C}$ to $0^{\circ} \mathrm{C}$.

\section{Results and Discussion}

\section{Instrument Response}

When the instruments were suspended in air, there was a small positive effect of temperature on $\varepsilon_{r}^{\prime}$, while the effect on $\varepsilon_{\mathrm{r}}^{\prime \prime}$ was negligible. Ideally, the measured $\varepsilon_{\mathrm{r}}^{\prime}$ would be 1 for all temperatures because the $\varepsilon_{\mathrm{r}}^{\prime}$ of air is 1 and is not affected by temperature. The response of all three sensors was similar and well described $\left(R^{2}=0.99\right)$ by the equation

$\varepsilon_{\mathrm{r}}^{\prime}=1.205+0.00456 T+0.0001908 T^{2}$

where $T$ is the air temperature in ${ }^{\circ} \mathrm{C}$.

If we assume that this response is a result only of the instrument components and therefore applicable to all measurements, the impact of the instrument temperature effect on calculated $\theta$ can be estimated from the $\varepsilon_{r}^{\prime}(\theta)$ relationship. Because the $\varepsilon_{r}^{\prime}(\theta)$ relationship is nonlinear, the impact of this effect varies with $\theta$. We illustrate this for a $40^{\circ} \mathrm{C}$ temperature change (from 5 to $45^{\circ} \mathrm{C}$ ) in Fig. 1 using the general $\varepsilon_{r}^{\prime}(\theta)$ calibration equation from Seyfried et al. (2005). We found that, with this fairly extreme change, the instrument effect is greater than $0.01 \mathrm{~m}^{3} \mathrm{~m}^{-3}$ in dry soil. At higher water contents instrument temperature effects
TABLE 1. Properties of soils tested.

\begin{tabular}{|c|c|c|c|c|c|c|c|}
\hline $\begin{array}{l}\text { NRCS ID } \\
\text { no.† }\end{array}$ & State & Site & Depth & Clay & Sand & Mineralł & Horizon \\
\hline & & & $\mathrm{cm}$ & - & - & & \\
\hline 2030 & AR & Lonoke Farm & 20 & 15.1 & 7.6 & ND & A \\
\hline \multirow[t]{3}{*}{2026} & & Walnut Gulch & 10 & 11.7 & 70 & ND & $A$ \\
\hline & & & 25 & 22.4 & 48.2 & ND & $\mathrm{Bk} 1$ \\
\hline & & & 50 & 21 & 40.4 & ND & Bk2 \\
\hline \multirow[t]{3}{*}{2013} & GA & Watkinsville & 5 & 10.8 & 73.8 & KK & Ap1 \\
\hline & & & 50 & 63.2 & 25.4 & GI,KK & Bt1 \\
\hline & ID & Breaks & 30 & 17 & 59 & ND & A3 \\
\hline \multirow[t]{2}{*}{2010} & MS & Newton (21) & 10 & 6.3 & 45.5 & $\mathrm{KK}, \mathrm{VR}$ & Ap \\
\hline & & & 20 & 6.4 & 49.6 & ND & $E$ \\
\hline \multirow[t]{6}{*}{2033} & MS & Onward (25) & 5 & 27.8 & 6.2 & MT & Ap \\
\hline & & & 20 & 35.8 & 3.8 & ND & $\mathrm{Bg}$ \\
\hline & & & 50 & 10.9 & 21.7 & ND & Bw \\
\hline & MS & Tunica (26) & 20 & 30.8 & 27.4 & MT & $\mathrm{A} 1$ \\
\hline & & & 50 & 42.7 & 1.5 & MT & $\mathrm{BgB1}$ \\
\hline & OK & Little Washita & 50 & 20.4 & 26.4 & ND & ND \\
\hline 2041 & VT & Mt. Mansfield & $0-3$ & & & organic & Oi \\
\hline \multirow[t]{3}{*}{2027} & GA & Little River & 5 & 2.8 & 88.1 & ND & Ap \\
\hline & OK & Fort Reno & 10 & 15 & 67 & ND & Ap \\
\hline & & & 50 & 35 & 47 & ND & $\mathrm{Bt}$ \\
\hline 2031 & IA & Ames & 5 & 36 & 17.6 & MT & A \\
\hline
\end{tabular}

† NRCS, Natural Resource Conservation Service.

$\ddagger$ Dominant clay mineral, ND = not determined, $\mathrm{KK}=$ kaolinite, $\mathrm{GI}=$ gibbsite, $\mathrm{VR}=$ vermiculite, $\mathrm{MT}=$ montmorillonite.

were much lower. For a $20^{\circ} \mathrm{C}$ change the effects are less than $0.01 \mathrm{~m}^{3} \mathrm{~m}^{-3}$ for all water contents.

\section{Oven-Dry Soil}

In all oven-dry soils we observed a small, nonlinear positive $\varepsilon_{r}^{\prime}$ temperature response. Although this was a consistent trend, on 10 of the 60 soil-replicate combinations there was a discontinuous, unexplained $\varepsilon_{r}^{\prime}$ drop at the highest temperature recorded $\left(45^{\circ} \mathrm{C}\right)$. Disregarding those readings, the magnitude and direction of the temperature response was practically equivalent to that observed in air, so that when the oven-dry data were corrected to account for the instrument temperature sensitivity using Eq. [7], no temperature response was observed (Fig. 2).

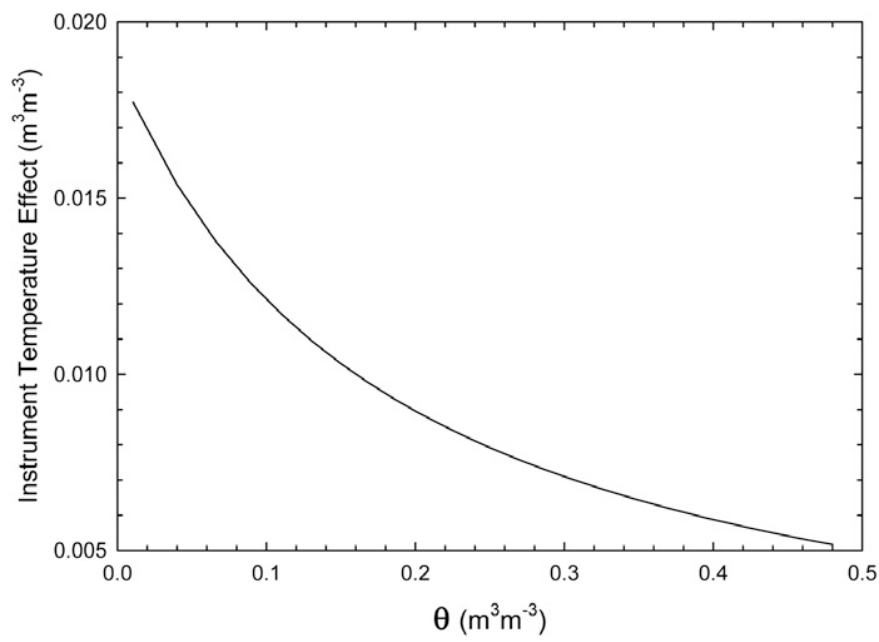

FIG. 1. Instrument temperature effect, defined here as the apparent change in soil water content $(\theta)$ due to Hydra Probe electrical components when subjected to a $40^{\circ} \mathrm{C}$ temperature change, plotted as a function of the actual water content. For example, if soil at $0.30 \mathrm{~m}^{3}$ $\mathrm{m}^{-3}$ experiences a temperature change of 5 to $45^{\circ} \mathrm{C}$, the instrument effect will cause an apparent water content rise of about 0.007 to $0.307 \mathrm{~m}^{3} \mathrm{~m}^{-3}$. 


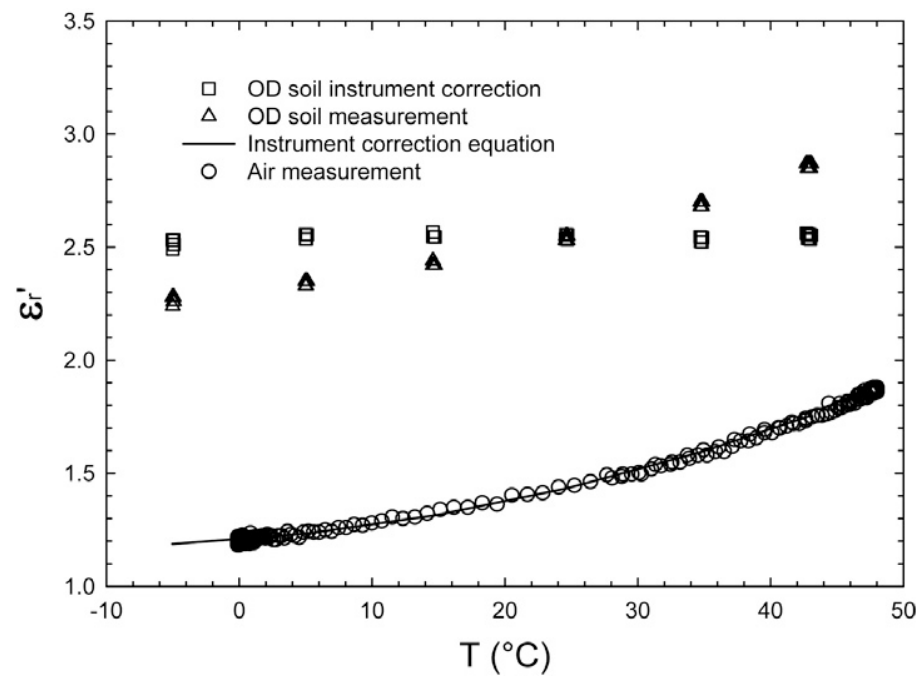

FIG. 2. Oven-dry (OD) soil corrected for instrument effects. The instrument correction equation (Eq. [7]) was fitted to the air data. After correcting for instrument effects to $25^{\circ} \mathrm{C}, \varepsilon_{r}^{\prime}$, the real component of relative complex permittivity, is essentially independent of temperature and slightly greater than 2.5 .

This result indicates that oven-dry soils are insensitive to temperature change, which is expected for the air and solid constituents. The instrument-corrected oven-dry $\varepsilon_{\mathrm{r}}^{\prime}$ values for the 19 mineral soils ranged from 2.47 to 2.99 , with a mean of 2.70 and standard deviation of 0.130 , which is consistent with TDR data reported in the literature (Hook and Livingston, 1995). The temperature effect on measured $\varepsilon^{\prime \prime}$ was an order of magnitude less than that observed for $\varepsilon_{\mathrm{r}}^{\prime}$ and was therefore ignored.

\section{Effective Saturation}

\section{Real Component}

We used eight soils to represent the $\varepsilon_{\mathrm{r}}^{\prime}$ temperature response at effective saturation for the 19 soils examined (Fig. 3). In all cases the $\varepsilon_{r}{ }^{\prime}$ value plotted is corrected for instrument temperature sensitivity using Eq. [7]. Values among soils are displaced vertically due to variations in the effective saturation, which is largely a function of clay content. For each soil, the average value of three sensors is plotted. Twenty values for each soil-temperature combination are plotted, but individual values are practically indistinguishable because of the low degree of variability among averaged values.

The response of all soils was roughly linear, with slopes ranging from slightly positive to slightly negative and some soils essentially insensitive to temperature. For the measured temperature range of 5 to $45^{\circ} \mathrm{C}$, the largest positive $\varepsilon_{\mathrm{r}}^{\prime}$ change was 3.7 , and the largest negative change was -2.0 among all soils. The lower value is in close agreement with what is calculated using the mixing model equation as suggested by Roth et al. (1990) and used by Seyfried and Murdock (2001) to describe temperature effects in sand. That equation can be written as

$\sqrt{\varepsilon_{\mathrm{r}}^{\prime}}=\theta \sqrt{\varepsilon_{\mathrm{r}, \mathrm{w}}^{\prime}(T)}+\theta_{\mathrm{s}} \sqrt{\varepsilon_{\mathrm{r}, \mathrm{s}}^{\prime}}+\theta_{\mathrm{g}} \sqrt{\varepsilon_{\mathrm{r}, \mathrm{g}}^{\prime}}$

where $\theta\left(\mathrm{m}^{3} \mathrm{~m}^{-3}\right)$ is the volumetric fraction and $\varepsilon_{\mathrm{r}}{ }^{\prime}$ the relative real permittivity of soil constituents denoted by the subscripts $\mathrm{w}$ for water, $\mathrm{g}$ for gas, and $\mathrm{s}$ for solids. ( $\theta$, without subscript, is used to denote soil water content, consistent with the text). The $\varepsilon_{\mathrm{r}, \mathrm{w}}{ }^{\prime}$ $(T)$ term represents the temperature effect on pure water and was calculated as (Weast, 1986):

$$
\begin{aligned}
\varepsilon_{\mathrm{r}, \mathrm{w}}^{\prime}= & 78.54\left[1-4.58 \times 10^{-3}(T-25)\right. \\
& \left.+1.19 \times 10^{-5}(T-25)^{2}-2.8 \times 10^{-8}(T-25)^{3}\right]
\end{aligned}
$$

If we use the measured values of $\theta=0.28 \mathrm{~m}^{3} \mathrm{~m}^{-3}$ and $\theta_{\mathrm{a}}=0.05$, and assume $\varepsilon_{r, s}{ }^{\prime}=5$ for the Tifton soil, we calculate an $\varepsilon_{\mathrm{r}}{ }^{\prime}$ change of -1.8 when temperature increases from 5 to $45^{\circ} \mathrm{C}$, which is close to the -2.0 observed. The neutral to positive changes in other soils indicate that the soil water system does not behave as if it were composed of pure water and inert soil.

When $\varepsilon_{r}^{\prime}$ values were converted to $\theta$ using previously developed calibrations (Seyfried et al., 2005), the effects of temperature were reasonably well described as a linear function of temperature, with $R^{2}$ values greater than 0.80 apart from four soils for which the slope $\mathrm{d} \theta / \mathrm{d} T$ was essentially 0 . This linear temperature dependence is consistent with what others have reported for TDR (Persson, and Berndtsson, 1998; Logsdon, 2000, 2005b). The slope $\mathrm{d} \theta / \mathrm{d} T$ ranged from 0.0007 to $-0.0007 \mathrm{~m}^{3} \mathrm{~m}^{-3}{ }^{\circ} \mathrm{C}^{-1}$. This corresponds to a calculated $\theta$ change of $0.028 \mathrm{~m}^{3} \mathrm{~m}^{-3}$ for a $40^{\circ} \mathrm{C}$ temperature change.

There is no equation analogous to Eq. [8] to calculate the upper limit for positive temperature effects. However, the $\mathrm{d} \theta / \mathrm{d} T$ slopes we calculate for these soils are within the range of values reported for TDR in high clay-content, smectitic soils (Persson, and Berndtsson, 1998; Logsdon, 2000). Previous research (Seyfried and Murdock, 2001) indicates that the $d \theta / d T$ slopes are greatest (in absolute value) when the soil is saturated. This indicates that for many field conditions, temperature effects on $\theta$ values calculated from Hydra Probe measurements, although observable, will not be substantial. That is, for most soils, the absolute value of $\mathrm{d} \theta / \mathrm{d} T$ will be less than $0.0007 \mathrm{~m}^{3} \mathrm{~m}^{-3}{ }^{\circ} \mathrm{C}^{-1}$,

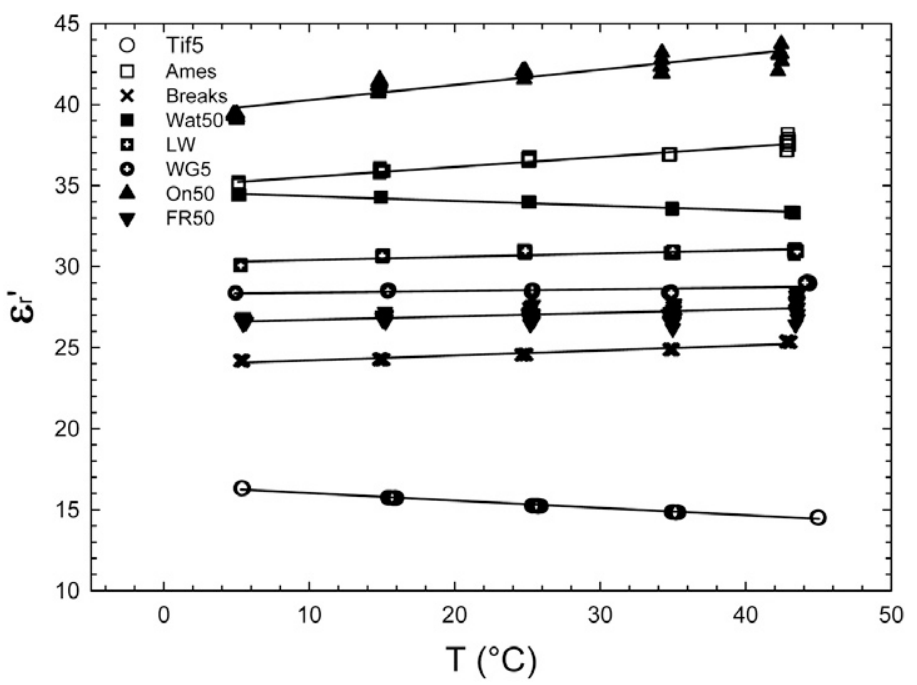

FIG. 3. Effect of temperature on $\varepsilon_{r}^{\prime}$ (real component of relative complex permittivity) for eight representative soils (Tif5 = Little River, $5 \mathrm{~cm}$; Ames =Ames, $5 \mathrm{~cm}$; Breaks = Breaks, $30 \mathrm{~cm}$; Wat50 = Watkinsonville, $50 \mathrm{~cm}$; LW = Little Washita, $50 \mathrm{~cm}$; WG5 = Walnut Gulch, $5 \mathrm{~cm}$; On50 = Onward, $50 \mathrm{~cm}$; and FR50 = Fort Reno, $50 \mathrm{~cm}$; see Table 1). Each point is the average of data from three individual sensors. Twenty measurements were made at each temperature. Lines represent the linear temperature effect for each soil. 
the temperature range experienced will often be less than $40^{\circ} \mathrm{C}$, and the soil will probably not be saturated much of the year. All of these conditions will tend to reduce the temperature effect range to less than $0.028 \mathrm{~m}^{3} \mathrm{~m}^{-3}$.

Imaginary Component

For all soils and all sensors, the effect of temperature on $\varepsilon_{r}^{\prime \prime}$ was remarkably linear and always positive. For 16 of the 19 soils investigated, linear regression of $\varepsilon_{\mathrm{r}}^{\prime \prime}$ on temperature resulted in $R^{2}$ values greater than 0.99 ; for the remaining three soils, the $R^{2}$ values were greater than 0.93 . The soils represented in Fig. 4, which are the same as those in Fig. 3, exemplify the linearity and range of slopes observed among soils. Slopes $\left(\mathrm{d} \varepsilon_{\mathrm{r}}^{\prime \prime} / \mathrm{d} T\right) \mathrm{calcu}-$ lated from regression analysis ranged from 0.10 to 1.11 , almost six times greater than that obtained for $\mathrm{d} \varepsilon_{\mathrm{r}}{ }_{\mathrm{r}}^{\prime} / \mathrm{d} T$. Also note that $\varepsilon_{\mathrm{r}}^{\prime \prime}$ values, at any temperature, are correlated with the $\mathrm{d} \varepsilon_{\mathrm{r}}^{\prime \prime} / \mathrm{d} T$ slope (the $R^{2}$ between the slope and $y$ intercept is 0.97).

We noted previously (Seyfried et al., 2005) that $\varepsilon_{\mathrm{r}}^{\prime \prime}$ varies more among soils than $\varepsilon_{\mathrm{r}}^{\prime}$. Here we found that it also varies much more with temperature. From these data, it is clear that soil dielectric moisture sensors operating at frequencies near 50 $\mathrm{MHz}$ that respond to a composite of $\varepsilon_{\mathrm{r}}^{\prime}$ and $\varepsilon_{\mathrm{r}}^{\prime \prime}$ (e.g., Eq. [3]) have a great potential for positive temperature sensitivity. We illustrate this with data from the Ames soil, which has a strong $\varepsilon_{\mathrm{r}}^{\prime \prime}$ temperature response relative to $\varepsilon_{\mathrm{r}}^{\prime}$ (Fig. 5). The $\varepsilon_{\mathrm{a}}$ calculated from Eq. [3] varies from 41 to 57 as temperature changes from 5 to $43^{\circ} \mathrm{C}$. Using a previously developed calibration equation (Seyfried et al., 2005), this corresponds to an apparent $\theta$ change of $0.117 \mathrm{~m}^{3} \mathrm{~m}^{-3}$ or a $\mathrm{d} \theta / \mathrm{d} T$ of $0.0031 \mathrm{~m}^{3} \mathrm{~m}^{-3}{ }^{\circ} \mathrm{C}^{-1}$, considerably more than the apparent $\theta$ change of $0.021 \mathrm{~m}^{3} \mathrm{~m}^{-3}$ or a $\mathrm{d} \theta / \mathrm{d} T$ of $0.00056 \mathrm{~m}^{3} \mathrm{~m}^{-3}{ }^{\circ} \mathrm{C}^{-1}$ calculated from $\varepsilon_{\mathrm{r}}^{\prime}$. These dramatic temperature effects on $\varepsilon_{a}$ are consistent with data reported by Seyfried and Murdock (2001) in which the $d \theta / d T$ for an unsaturated sample was $0.0039 \mathrm{~m}^{3} \mathrm{~m}^{-3}{ }^{\circ} \mathrm{C}^{-1}$, and more recently by Evett et al. (2006), who reported even greater tem-

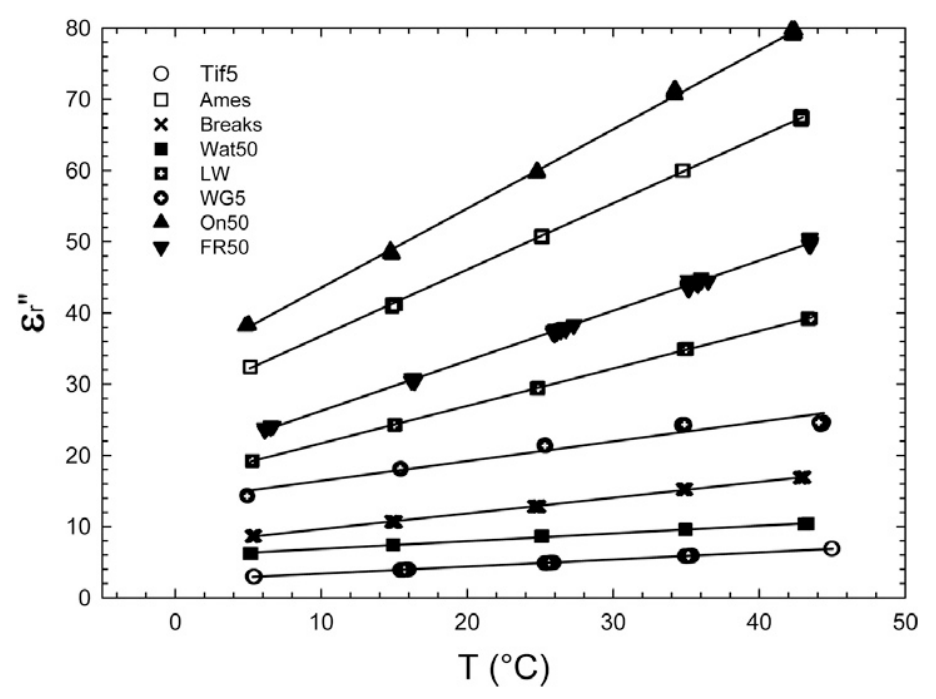

FIG. 4. Effect of temperature on $\varepsilon_{\mathrm{r}}^{\prime \prime}$ (imaginary component of relative complex permittivity) for eight representative soils (Tif5 = Little River, $5 \mathrm{~cm}$; Ames =Ames, $5 \mathrm{~cm}$; Breaks $=$ Breaks, $30 \mathrm{~cm}$; Wat50 = Watkinsonville, 50 $\mathrm{cm}$; LW = Little Washita, $50 \mathrm{~cm}$; WG5 = Walnut Gulch, $5 \mathrm{~cm}$; On50 = Onward, $50 \mathrm{~cm}$; and FR50 = Fort Reno, $50 \mathrm{~cm}$; see Table 1). Each temperature $-\varepsilon_{r}^{\prime \prime}$ combination is represented by 12 to 15 measurements.

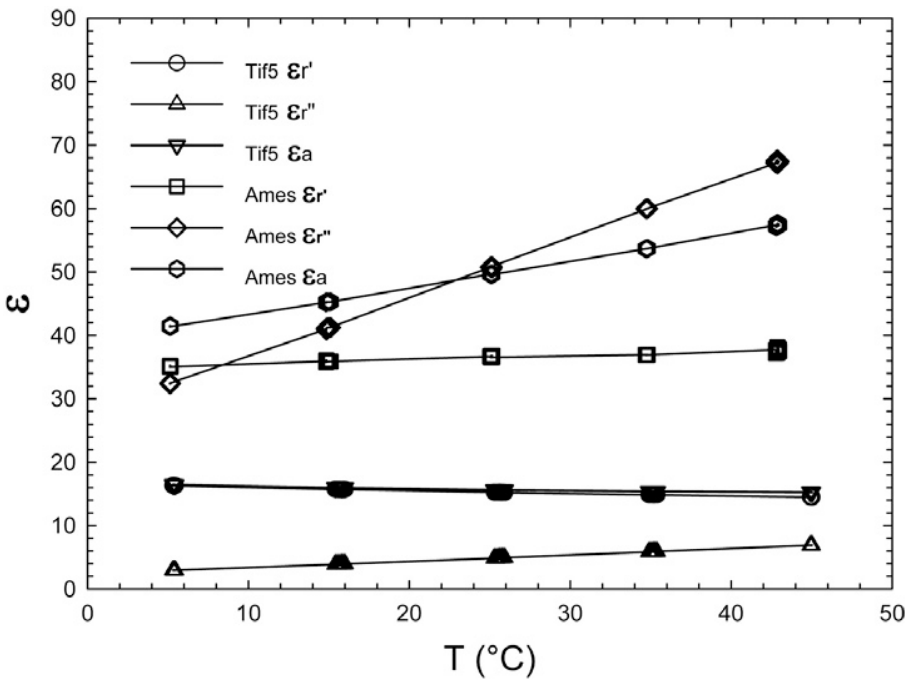

FIG. 5. Comparison of the measured $\varepsilon_{r}^{\prime}$ (real component of relative complex permittivity) and $\varepsilon_{\mathrm{r}}^{\prime \prime}$ (imaginary component of relative complex permittivity) temperature $(T)$ response with apparent permittivity, $\varepsilon_{\mathrm{a}}$, calculated using Eq. [3]. The Ames soil is representative of high $\varepsilon_{r}^{\prime \prime}$ soils, and the Tif5 soil is representative of low $\varepsilon_{r}^{\prime \prime}$ soils. Where $\varepsilon_{r}^{\prime \prime}$ is low, there is little impact on $\varepsilon_{a}$, and sensor type is not critical.

perature sensitivity. In contrast, similar $\varepsilon_{a}$ calculations for the Tifton soil, which has a negative temperature response, indicate that sensor type is not critical for low $\varepsilon_{\mathrm{r}}^{\prime \prime}$ soils because $\varepsilon_{\mathrm{r}}^{\prime}$ and $\varepsilon_{\mathrm{a}}$ are practically indistinguishable.

We cannot determine from Hydra Probe data alone the relative contribution of $\varepsilon^{\prime \prime}{ }_{\mathrm{r}, \mathrm{mr}}$ or $\sigma$ to $\varepsilon_{\mathrm{r}}^{\prime \prime}$. One can express $\varepsilon_{\mathrm{r}}^{\prime \prime}$ as either purely relaxation or purely conductivity using Eq. [4]. For example, following von Hippel (1995), $\varepsilon_{r}^{\prime \prime}$ can be described as the dielectric conductivity $\left(\sigma_{\mathrm{d}}\right)$, with units of $\mathrm{d} S \mathrm{~m}^{-1}$, as

$\sigma_{\mathrm{d}}=\varepsilon_{0} \varepsilon_{\mathrm{r}}^{\prime \prime} f 2 \pi$

If the contribution of $\varepsilon^{\prime \prime}{ }_{\mathrm{r}, \mathrm{mr}}$ is very small, $\sigma_{\mathrm{d}}$ calculated in this way should be equivalent to the electrical conductivity. We have shown this to be true for Hydra Probe measurements in aqueous salt solutions for $\sigma$ values up to $\sim 3.5 \mathrm{dS} \mathrm{m} \mathrm{m}^{-1}$ (Seyfried and Murdock, 2004).

The advantage of considering $\varepsilon_{r}^{\prime \prime}$ in terms of $\sigma_{d}$ is that the temperature response of electrical conductivity is fairly well documented (Sheets and Hendrickx, 1995; Or and Wraith, 1999), thus enabling the estimation of temperature effects. Some evidence in the literature indicates that $\sigma$ dominates the $\varepsilon_{r}^{\prime \prime}$ signal at $50 \mathrm{MHz}$ (Robinson et al., 2005; Campbell, 1990; Hasted, 1973). If this is the case for soils in general, then the slope $\mathrm{d} \sigma_{\mathrm{d}} /$ $\mathrm{d} T$ determined from Hydra Probe measurements and Eq. [10] should be approximately equal to $\mathrm{d} \sigma / \mathrm{d} T$ calculated with standard relationships used for soils.

We tested this approach using the temperature correction equation of Sheets and Hendrickx (1995). They calculate $\sigma_{25}$, the electrical conductivity corrected to $25^{\circ} \mathrm{C}$, with a correction factor $C_{T}$, such that

$$
\sigma_{25}=C_{T} \sigma, \quad C_{T}=0.447+1.4034 \mathrm{e}^{(-T / 26.815)}
$$


The slope $\mathrm{d} \sigma / \mathrm{d} T$ predicted with this approach is highly linear, with a value of $0.019 \mathrm{~S} \mathrm{~m}^{-1} \mathrm{C}^{-1}$, which is very similar to that used by others (Kelleners et al., 2005; Or and Wraith, 1999). After converting $\varepsilon_{\mathrm{r}}^{\prime \prime}$ measurements to $\sigma_{\mathrm{d}}$, we found that temperature effects were strongly linear with an average $\mathrm{d} \sigma_{\mathrm{d}} / \mathrm{d} T$ for all soils of $0.018 \mathrm{~S} \mathrm{~m}^{-1} \mathrm{C}^{-1}$. Soils with a relatively high $\sigma_{25}$ tended to agree with Eq. [11] most closely (Fig. 6). Deviation from slopes of $0.019 \mathrm{~S} \mathrm{~m}^{-1} \mathrm{C}^{-1}$ implies that mechanisms other than electrical conductivity contribute to $\varepsilon_{\mathrm{r}}^{\prime \prime}$ in those soils, which is consistent with observations of Kelleners et al. (2005) and Logsdon (2005a). Recent research by Chen and Or (2006) has shown that electrical conductivity and molecular relaxation are intimately linked through the process of interfacial polarization, so that ultimately, temperature effects may be very difficult to predict. As a practical matter, however, predictions of $\sigma_{25}$ based on Eq. [11] did not generate large errors for any of the soils tested and so may provide a reasonable basis for estimating temperature effects. Although our data are only for effective saturation, it is reasonable to expect that it would hold for other water contents as well.

\section{Water Content Temperature Effects and $\varepsilon_{\mathrm{r}}^{\prime \prime}$}

The data plotted in Fig. 7 relate the slope of the apparent water content response to temperature $(\mathrm{d} \theta / \mathrm{d} T)$ for all 19 mineral soils to the $\varepsilon_{\mathrm{r}}^{\prime \prime}$ measured at $25^{\circ} \mathrm{C}\left(\varepsilon^{\prime \prime}{ }_{\mathrm{r} 25}\right)$. The choice of $x$ axis is somewhat arbitrary in that we could use other measures of $\varepsilon_{\mathrm{r}}^{\prime \prime}$ such as the $y$-intercept or slope and achieve approximately the same result due to the high correlation among those variables. The relationship is roughly linear over the whole range $\left(R^{2}=\right.$ $0.81)$, although the correlation is much better for the relatively high $\varepsilon_{\mathrm{r}}^{\prime \prime}(>10)$ soils.

Negative slopes in Fig. 7 characteristic of the low $\varepsilon^{\prime \prime}{ }_{\mathrm{r} 25}$ soils are consistent with previous research in sands (Pepin et al., 1995) and the assumption that bulk soil dielectric properties can be approximated assuming that soil particles are inert and the soil solution has dielectric properties of pure water (e.g., Eq. [8]). Different mechanisms have been proposed to explain observed temperature effects on $\theta$ (Persson and Berndtsson, 1998; Or and Wraith, 1999; Robinson et al., 2005; Chen and Or, 2006). For Hydra Probe measurements, these effects are not directly related to $\varepsilon_{\mathrm{r}}^{\prime \prime}$ as they are with instruments that respond to both components (e.g., Eq. [3]), which explains why the Hydra Probe is insensitive to temperature relative to other, low-frequency instruments. The connection rather appears to be the result of interfacial polarization, as recently described by Chen and Or (2006). Basically, an increasing temperature causes the electrical conductivity to increase (as described previously), which then enhances interfacial polarization, increasing $\varepsilon_{\mathrm{r}}{ }^{\prime}$. Thus temperature, $\varepsilon_{\mathrm{r}}^{\prime \prime}, \varepsilon_{\mathrm{r}}^{\prime}$, and $\theta$ calculations are linked in a complex manner that is sensitive to soil properties.

Given the relationship shown in Fig. 7 and the fact that the Hydra Probe provides measurements of $\varepsilon_{r}^{\prime}, \varepsilon_{r}^{\prime \prime}$, and temperature, it should be possible to use $\varepsilon_{\mathrm{r}}^{\prime \prime}$ values to calculate the temperature response of a given soil at any time in the field. This approach has the great advantage of predicting temperature effects without requiring a detailed understanding of the interactions within the soil solution

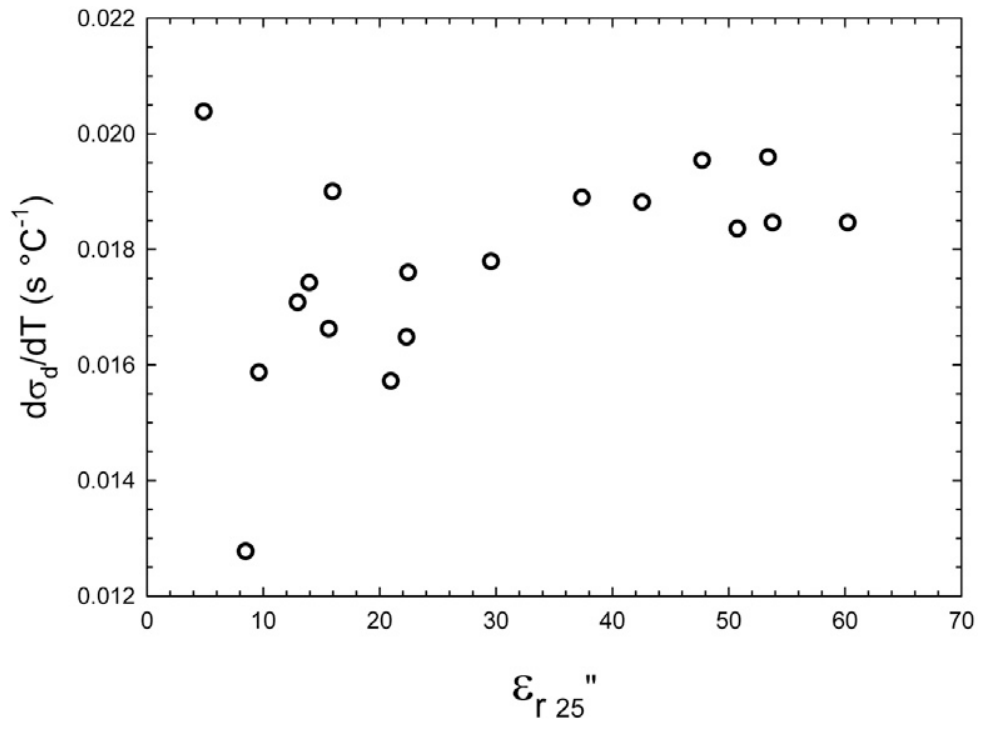

FIG. 6. The temperature $(T)$ response of $\sigma_{d}$ (dielectric conductivity) as a function of $\varepsilon_{\mathrm{r}}^{\prime \prime}$ (imaginary component of relative complex permittivity) measured at $25^{\circ}\left(\varepsilon_{\mathrm{r} 25^{\prime \prime}}\right)$. The soils with relatively high $\varepsilon_{\mathrm{r}}^{\prime \prime}$ respond as if all losses were from $\sigma$. Even at lower values, the difference between the $\mathrm{d} \sigma_{\mathrm{d}} / \mathrm{d} T$ slope and 0.019 is small.

and between clay surfaces that lead to soil-specific responses. Unfortunately, the data presented here apply only to effectively saturated soil. It is well known that electrical conductivity is highly sensitive to changes in $\theta$, and it is not clear how those changes will affect the relationship between $\mathrm{d} \theta / \mathrm{d} T$ and $\varepsilon_{\mathrm{r}}^{\prime \prime}$. A more practical application of this information awaits a more comprehensive understanding of $\varepsilon_{\mathrm{r}}^{\prime \prime}, \theta$, and temperature interactions. In the meantime, the relationship illustrated in Fig. 7 can be regarded as qualitative guide to the magnitude of temperature effects that might be expected in soils.

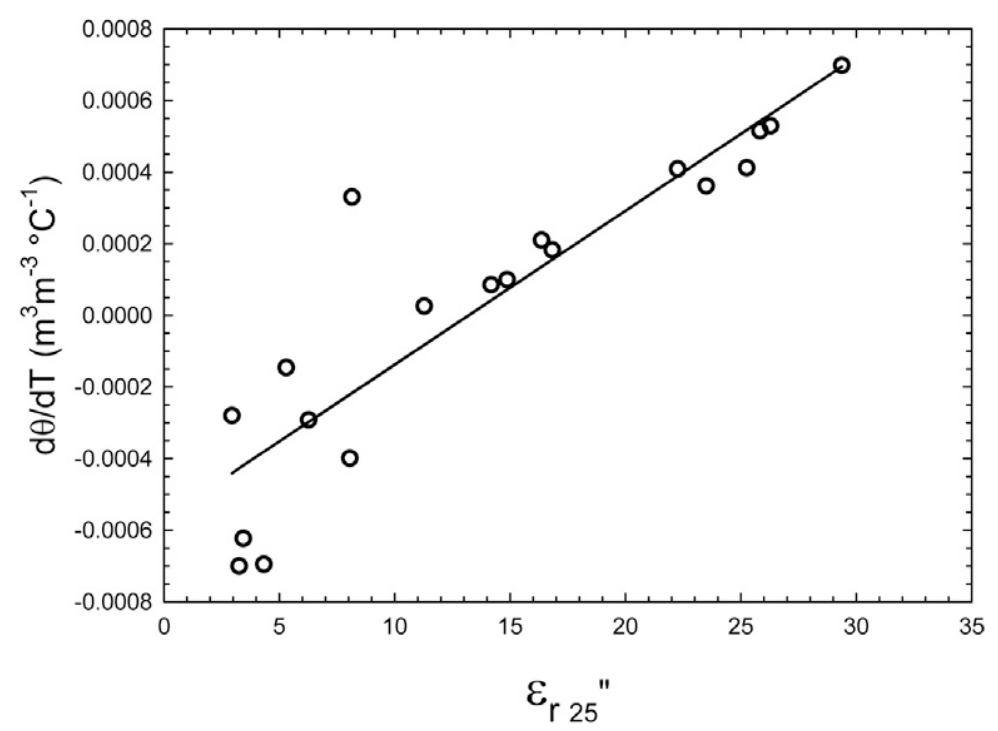

FIG. 7. The effect of temperature $(T)$ on estimated soil water content $(\theta)$, quantified by $\mathrm{d} \theta / \mathrm{d} T$, as a function of $\varepsilon_{\mathrm{r} 25^{\prime \prime}}$ (imaginary component of relative complex permittivity measured at $25^{\circ} \mathrm{C}$ ). Although there is considerable scatter about this relationship, especially for relatively low values of $\varepsilon_{\mathrm{r} 25^{\prime \prime}}$, it is clear that positive temperature effects are associated with high $\varepsilon_{\mathrm{r} 25}$ " values. 


\section{Conclusions}

We documented the $\varepsilon_{\mathrm{r}}^{\prime}$ and $\varepsilon_{\mathrm{r}}^{\prime \prime}$ temperature sensitivity of 19 mineral soil samples representing a wide range of texture and mineralogy when measured at $50 \mathrm{MHz}$ with the Hydra Probe. With respect to $\varepsilon_{\mathrm{r}}^{\prime}$, we found a small, nonlinear temperature response that is apparently a result of the instrument components. This effect is small enough to be ignored for many applications, or can be taken into account. In oven-dry soil, no temperature effect was observed if instrument effects were considered. In saturated soil, temperature responses were both positive and negative for different soils. When converted to water content, the response was linear and fell between -0.028 and $0.028 \mathrm{~m}^{3} \mathrm{~m}^{-3}$ for temperatures ranging from 5 to $45^{\circ} \mathrm{C}$. The lower (negative) extreme among soils was in close agreement to that predicted assuming the dielectric properties of the soil solution were equivalent to those of pure water. Positive temperature effects were within the range reported for clay soils and TDR.

In all soils investigated, there was a distinct, highly linear relationship between $\varepsilon_{\mathrm{r}}^{\prime \prime}$ and temperature in the saturated samples (negligible in oven-dry samples). The range in magnitude of $\varepsilon_{\mathrm{r}}^{\prime \prime}$ and of temperature effects was much greater than that observed for $\varepsilon_{\mathrm{r}}^{\prime}(T)$ with the same samples. This explains the extreme temperature sensitivity exhibited by some instruments that do not distinguish $\varepsilon_{\mathrm{r}}^{\prime}$ from $\varepsilon_{\mathrm{r}}^{\prime \prime}$ but respond to both. It also indicates that those instruments will experience highly variable temperature effects among different soils.

When $\varepsilon_{\mathrm{r}}^{\prime \prime}$ was expressed as $\sigma_{\mathrm{d}}$, we found that the temperature response was similar to that predicted for $\sigma$ in general, implying that $\sigma$ is largely responsible for the measured $\varepsilon_{\mathrm{r}}^{\prime \prime}$ values. The positive correlation between the magnitude of $\varepsilon_{r}^{\prime \prime}$ and the $\theta$ (and therefore $\varepsilon_{r}^{\prime}$ ) temperature response is consistent with interfacial polarization as a dispersion mechanism at $50 \mathrm{MHz}$, which is directly related to $\sigma$. This documented relationship between the $\theta$ temperature response and $\varepsilon_{\mathrm{r}}^{\prime \prime}$ indicates that there is a potential for estimating temperature response based on $\varepsilon_{r}^{\prime \prime}$ data. Before this can be accomplished, however, the interactions between $\theta, \varepsilon_{\mathrm{r}}^{\prime}$, and $\varepsilon_{\mathrm{r}}^{\prime \prime}$ must be also be considered.

\section{References}

Baumhardt, R.L., R.J. Lascano, and S.R. Evett. 2000. Soil material, temperature, and salinity effects on calibration of multisensor capacitance probes. Soil Sci. Soc. Am. J. 64:1940-1946.

Blonquist, J.M., Jr., S.B. Jones, and D.A. Robinson. 2005. Standardizing characterization of electromagnetic water content sensors: Part 2. Evaluation of seven sensing systems. Vadose Zone J. 4:1059-1069.

Campbell, J.E. 1988. Dielectric properties of moist soils at RF and microwave frequencies. Ph.D. diss. Dartmouth College, Hanover, NH.

Campbell, J.E. 1990. Dielectric properties and influence of conductivity in soils at one to fifty Megahertz. Soil Sci. Soc. Am. J. 54:332-341.

Chen, Y., and D. Or. 2006. Effects of Maxwell-Wagner polarization on soil complex dielectric permittivity under variable temperature and electrical conductivity. Water Resour. Res. 42:W06424, doi:10.1029/ 2005WR004590.

Evett, S.R., J.A. Tolk, and T.A. Howell. 2005. TDR laboratory calibration in travel time, bulk electrical conductivity, and effective frequency. Vadose Zone J. 4:1020-1029.

Evett, S.R., J.A. Tolk, and T.A. Howell. 2006. Soil profile water content determination: Sensor accuracy, axial response, calibration, temperature dependence, and precision. Vadose Zone J. 5:894-907.

Friedman, S.P., and D.A. Robinson. 2002. Particle shape characterization using angle of repose measurements for predicting the effective permittivity and electrical conductivity of saturated granular media. Water Resour. Res.
38(11):1236, doi:10.1029/2001WR000746

Hasted, J.B. 1973. Aqueous dielectrics. Chapman and Hall, London, UK.

Hook, W.R., and N.J. Livingston. 1995. Errors in converting time domain reflectometry measurements of propagation velocity to estimates of soil water content. Soil Sci. Soc. Am. J. 59:35-41.

Jones, S.B., and S.P. Friedman. 2000. Particle shape effects on the effective permittivity of anisotropic or isotropic media consisting of aligned or randomly oriented ellipsoidal particles. Water Resour. Res. 36:28212833.

Kelleners, T.J., M.S. Seyfried, J.M. Blonquist, J. Bilskie, and D.G. Chandler. 2005. Improved interpretation of water content reflectomenter measurements in soils. Soil Sci. Soc. Am. J. 69:1684-1690.

Logsdon, S.D. 2000. Effect of cable length on time domain reflectometry calibration for high surface area soils. Soil Sci. Soc. Am. J. 64:54-61.

Logsdon, S.D. 2005a. Soil dielectric spectra from vector network analyzer data. Soil Sci. Soc. Am. J. 69:983-989.

Logsdon, S.D. 2005b. Time domain reflectometry range of accuracy for high surface area soils. Vadose Zone J. 4:1011-1019.

Or, D., and J.M. Wraith. 1999. Temperature effects on soil bulk dielectric permittivity measured by time domain reflectometry: A physical model. Water Resour. Res. 35:371-383.

Pepin, S., N.J. Livingston, and W.R. Hook. 1995. Temperature-dependent measurement errors in time domain reflectometry determinations of soil water. Soil Sci. Soc. Am. J. 59:38-43.

Persson, M., and R. Berndtsson. 1998. Texture and electrical conductivity effects on temperature dependency in time domain reflectometry. Soil Sci. Soc. Am. J. 62:887-893.

Robinson, D.A., T.J. Kelleners, J.D. Cooper, C.M.K. Gardner, P. Wilson, I. Lebron, and S. Logsdon. 2005. Evaluation of a capacitance probe frequency response model accounting for bulk electrical conductivity: Comparison with TDR and network analyzer measurements. Vadose Zone J. 4:992-1003.

Robinson, D.A., S.B. Jones, J.M. Wraith, D. Or, and S.P. Friedman. 2003. A review of advances in dielectric and electrical conductivity measurement in soils using time domain reflectometry. Vadose Zone J. 2:444-475.

Roth, K., R. Schulin, H. Fluhler, and W. Attinger. 1990. Calibration of time domain reflectometry for water content measurement using a composite dielectric approach. Water Resour. Res. 26:2267-2273.

Saarenketo, T. 1998. Electrical properties of water in clay and silty soils. J. Appl. Geophys. 40:73-88.

Seyfried, M.S., L.E. Grant, E. Du, and K. Humes. 2005. Dielectric loss and calibration of the Hydra Probe soil water sensor. Vadose Zone J. 4:10701079.

Seyfried, M.S., and M.D. Murdock. 2001. Response of a new soil water sensor to variable soil, water content, and temperature. Soil Sci. Soc. Am. J. 65:28-34.

Seyfried, M.S., and M.D. Murdock. 2004. Measurement of soil water content with a 50- MHz soil dielectric sensor. Soil Sci. Soc. Am. J. 68:394-403.

Sheets, K.R., and J.M.H. Hendrickx. 1995. Non-invasive soil water content measurement using electromagnetic induction. Water Resour. Res. 31:2401-2409.

Tinga, W.R. 1992. Mixture laws and microwave-material interactions. p. 1-34. In A. Priou (ed.) Dielectric properties of heterogeneous materials. Progress in Electomagnetics Research no. 6. Elsevier, New York.

Topp, G.C., J.L. Davis, and A.P. Annan. 1980. Electromagnetic determination of soil water content: Measurement in coaxial transmission lines. Water Resour. Res. 16:574-582.

Topp, G.C., S. Zegelin, and I. White. 2000. Impact of real and imaginary components of relative permittivity on time domain reflectometry measurements in soils. Soil Sci. Soc. Am. J. 64:1244-1255.

von Hippel, A. 1995. Dielectric materials and applications. Artech House, London, UK.

Weast, R.C. (ed.). 1986. Handbook of physics and chemistry. 67th ed. CRC Press, Boca Raton, FL. 